\title{
Inductance Gradient Calculations of EMFY-3 Electromagnetic Launcher
}

This paper was downloaded from TechRxiv (https://www.techrxiv.org).

LICENSE

CC BY 4.0

SUBMISSION DATE / POSTED DATE

$19-08-2021 / 28-08-2021$

\section{CITATION}

Tosun, Nail; Keysan, Ozan (2021): Inductance Gradient Calculations of EMFY-3 Electromagnetic Launcher. TechRxiv. Preprint. https://doi.org/10.36227/techrxiv.15372999.v1

DOI

10.36227/techrxiv.15372999.v1 


\title{
Inductance Gradient Calculations of EMFY-3 Electromagnetic Launcher
}

\author{
Nail Tosun (D., Student Member, IEEE, Anıl Civil, Ahmet Yasin Oruç, Baran Yıldırım, Bekir Mert Özceylan, \\ Bora Bolat, Emre Burak Yurdakul, Evren Tan, Ferhat Yurdakonar, Hüseyin Akdemir, İbrahim Güngen, \\ İbrahim Önür, Mustafa Karagöz, Member, IEEE, Özgur Cavbozar, Rasih Hakan Demirkol, Ulaş Göçmen, \\ and Ozan Keysan (ID, Member, IEEE
}

\begin{abstract}
ASELSAN Inc. has been working on electromagnetic launch technologies since 2014. The first prototype, EMFY-1, has a $25 \mathrm{~mm} \times 25 \mathrm{~mm}$ square bore and 3-m-length rails. The second prototype, EMFY-2, has a $50 \times 50 \mathrm{~mm}$ square bore and 3-m-length. In this paper, a recently developed prototype, EMFY-3, is presented, which has a $50 \times 75 \mathrm{~mm}$ rectangular bore and 6-m-length. The input energy of the PPS is doubled to $8 \mathrm{MJ}$, and the $2.91 \mathrm{MJ}$ muzzle energy is obtained up to now. Rail currents, breech, and muzzle voltages are measured to investigate electromagnetic calculations. Velocity curves are captured with Doppler radar, which enables us to establish propulsive inductance gradient $L_{p r}^{\prime}$ transients empirically. The results confirm that $L_{p r}^{\prime}$ is constant throughout the launch, as no significant breaking mechanism occurs with the non-magnetic containment. However, a slight variation ( $\% 2$ at maximum) happens from one launch to another with different rails' current magnitudes. The transition phenomenon is a candidate for the drop in the $L_{p r}^{\prime}$, as it occurs more likely at launches with higher linear current densities.
\end{abstract}

Index Terms-Electromagnetic launchers (EMLs), finite element (FE) analysis, pulsed-power supply (PPS), railgun, muzzle voltage, transition.

\section{INTRODUCTION}

$\mathbf{E}$ Lectromagnetic launchers (EMLs) are an accelerator concept that transforms the stored electrical energy to linear kinetic energy. It consists of two conducting rails, an armature, and a projectile. A significant amount of pulse-shaped current provided by a pulsed-power supply (PPS) flows through rails and armature in a short duration (a few milliseconds) of time. Lorentz force acts on the armature as the EML seeks to maximize its inductance.

ASELSAN Inc. has been conducting experimental and theoretical research on EML technologies since 2014 [1]-[4]. Firstgeneration 1-MJ and second-generation 3.25-MJ PPSs were developed and tested with $25 \mathrm{~mm}$ x $25 \mathrm{~mm}$ bore EMFY-1 at an open area test range. EMFY-2 is built in the laboratory, an 8-MJ PPS system, a flash X-ray system, a 6-m-long catch tank, and diagnostic tools [5]. These two EMLs are used to improve electromagnetic analysis in terms of transient EMF calculations [6], and velocity skin effect (VSE) analysis [7].

N. Tosun, and O. Keysan are with Middle East Technical University, Department of Electrical and Electronics Engineering, Ankara, Turkey. Email: keysan@metu.edu.tr

A. Civil, A. Oruç, B. Bolat, B. Yıldırım, B. Özceylan, B. Yurdakul, E. Tan, F. Yurdakonar, H. Akdemir, H. Demirkol, İ. Güngen, İ. Onur, M. Özceylan, M. Karagöz, Ö. Cavbozar, and U. Göçmen are with ASELSAN Inc., Ankara 06370, Turkey (e-mail: mkaragoz@aselsan.com.tr).

Corresponding Author: Ozan Keysan, keysan@metu.edu.tr
TABLE I

GeOMETRIC PARAMETERS OF THE EMFY-3 LAUNCHER.

\begin{tabular}{lc}
\hline Rail Height & $50 \mathrm{~mm}$ \\
Rail Separation & $75 \mathrm{~mm}$ \\
Rail Length & $6.1 \mathrm{~m}$ \\
\hline
\end{tabular}

Propulsive inductance gradient, which is denoted as $\mathrm{L}_{\mathrm{pr}}^{\prime}$, is an essential parameter to characterize EML. It is directly linked to efficiency since additive inductance on the armature creates Lorentz force. If the containment surrounding rails is not electrically conducting, $\mathrm{L}_{\mathrm{pr}}^{\prime}$ is regarded as constant throughout the launch as there is no eddy breaking mechanism. EMFY-3 has a non-conductive composite containment material. EMFY-3 launcher is presented in Fig. 1. The geometric parameters of the launcher are shared in Table II Apart from previous EML experiments, the Doppler radar system is equipped to ASELSAN Laboratory to examine possible transients in $\mathrm{L}_{\mathrm{pr}}^{\prime}$. As the armature acceleration and rail currents are measurable, $\mathrm{L}_{\mathrm{pr}}^{\prime}$ can be calculated empirically. An et. al [8] stated that VSE induces the temporal variation of inductance gradient. However, they neglected aerodynamics and friction effect, which can influence launch dynamics. In this study, not only temporal changes are investigated, but also the launch dynamics are regarded.

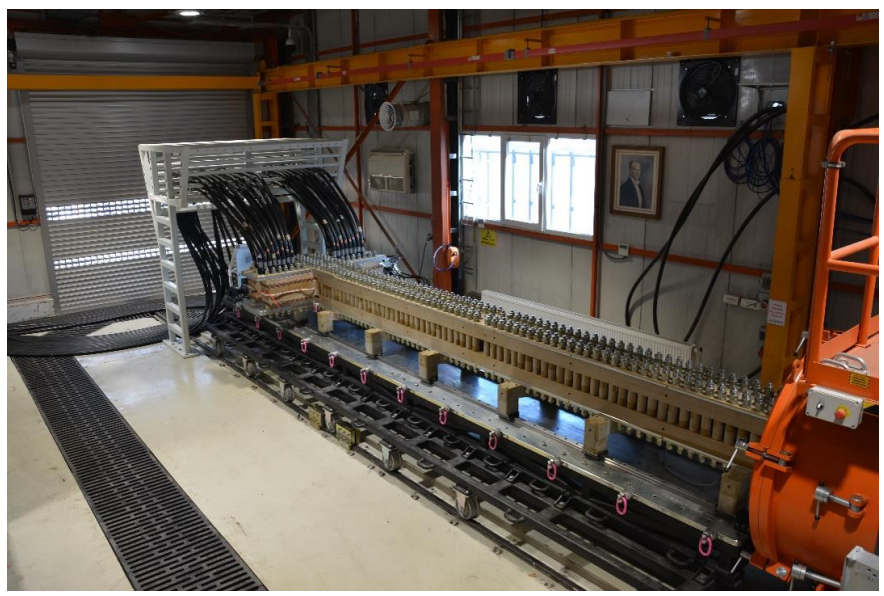

Fig. 1. EMFY-3 Launcher

Moreover, a sensitivity analysis is performed to study the importance of $\mathrm{L}_{\mathrm{pr}}^{\prime}$ calculation. A kine-mechanical model is constructed to model the armature acceleration. Three different 
tests are shared to demonstrate the reliability of the model, as well as to observe $\mathrm{L}_{\mathrm{pr}}^{\prime}$. It is observed that $\mathrm{L}_{\mathrm{pr}}^{\prime}$ tends to decline when the magnitude of the rail current is increased. However, the result is surprising, as there is no expected brake mechanism with a non-conductive containment. The first suspect for the loss/brake phenomenon is transition. The transition phenomenon is termed the transition of solid contact into arcing contact. Multiple mechanisms can induce transition. [9]-[12]. As the deficit at $\mathrm{L}_{\mathrm{pr}}^{\prime}$ is associated with maximum rail current density [13], the transition is the main candidate for such a loss mechanism. The deficit at the acceleration has occurred at the late stage of the launch, which is a shred of strong evidence for transition.

\section{Sensitivity Analysis}

In this section, the central focus is to investigate the sensitivity of the kine-mechanical calculations to propulsive inductance gradient $\mathrm{L}_{\mathrm{pr}}^{\prime}$ estimation errors. As in Fig. 2 , electromagnetic modeling of an EML can be approximated as a series-connected variable resistance and inductance. These variable circuit elements, the resistance and the inductance of EML denoted as $R_{E M L}$, and $L_{E M L}$, depends on the mechanical states. Therefore, the electromagnetic analysis depends profoundly on kine-mechanical calculations; any deviation from the actual value can cause a cumulative error in the system's total inductance and resistance calculations. As a doppler radar is used to obtain velocity measurements during the launch, the armature acceleration can be obtained, which can be linked with any possible $\mathrm{L}_{\mathrm{pr}}^{\prime}$ transients. The propulsive force at the armature, which is denoted as $\vec{F}_{p r}$, can be determined by 1 , where $I_{\text {rail }}$ is the rail current.

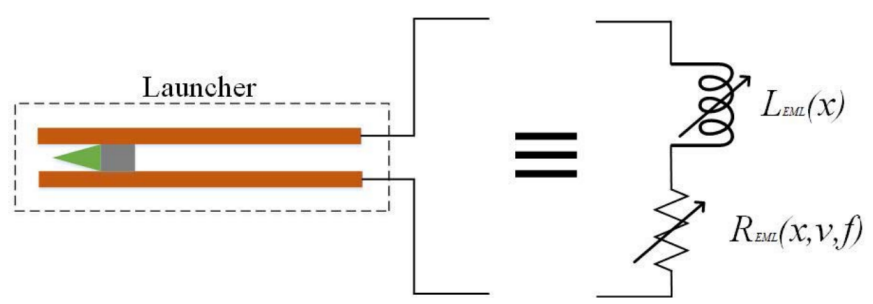

Fig. 2. Electromagnetic launcher can be modeled as series connected variable resistance and inductance.

$$
\vec{F}_{p r}=\frac{L_{p r}^{\prime} I_{r a i l}^{2}}{2}
$$

However, $\vec{F}_{p r}$ is not the only force that acts on the armature. Friction and drag forces denoted as $\vec{F}_{\text {fric }}$ and $\vec{F}_{\text {drag }}$ action in a direction that opposes the movement as in 2 . $\vec{F}_{\text {fric }}$ can be modelled as in (3) where $\mu_{d}$ and $\mu_{s}$ are dynamic and static friction coefficients respectively [14]. $\zeta$ is the friction damping factor, and $\vec{F}_{C}$ is the contact force. $\vec{F}_{\text {fric }}$ calculation is simplified considering their net influence on the launch. $\mu_{d}$ and $\mu_{s}$ are not constant throughout the launch; they depend on the contact state. When the liquid film starts to occur in the electrical contact, $\mu_{s}$ and $\mu_{d}$ diminish significantly. Moreover, the determination of $\zeta$ is challenging. However, assuming the contact transformation occurs at $t=0.5 \mathrm{~ms}$ gives coherent results with experimental findings. Dynamic variations of the friction coefficients are demonstrated in Fig. 3 as a function of time. The model parameters are given in Table III

$$
\begin{gathered}
\vec{F}_{n e t}=\max \left(0, \vec{F}_{p r}-\vec{F}_{f r i c}-\vec{F}_{d r a g}\right) \\
\vec{F}_{f r i c}=\left(\mu_{d}+\left(\mu_{s}-\mu_{d}\right) e^{\zeta-v}\right) \vec{F}_{C}
\end{gathered}
$$

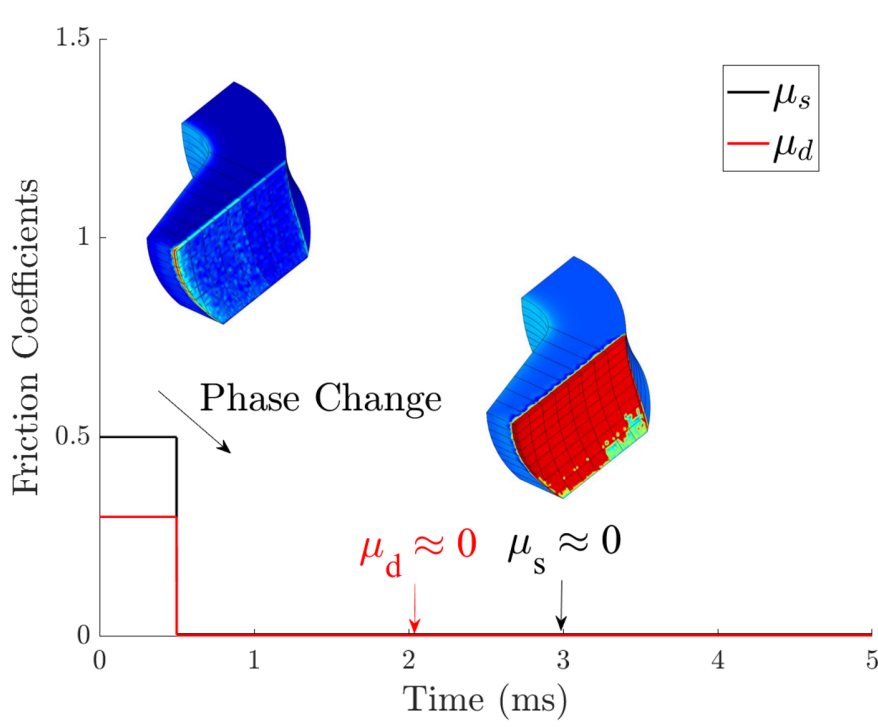

Fig. 3. Dynamic change of the friction coefficients as a function of time.

Two different drag mechanisms occur at the launch package. These are named electromagnetic drag and aerodynamic drag. Aerodynamic drag is more straightforward than electromagnetic drag in terms of the analytical model's complexity. Aerodynamic drag, which is denoted as $\vec{F}_{d r a g}$ can be modeled as in (4). $\mathrm{C}_{\mathrm{d}}$ is the drag coefficient (it is a dimensionless quantity.), $\mathrm{A}_{\mathrm{lp}}$ is the area that frontier to the air, $\rho_{\text {air }}$ is the density of air.

$$
\vec{F}_{d r a g}=\frac{1}{2} C_{d} A_{l p} \rho_{a i r} v_{a r m}^{2}
$$

Electromagnetic drag is the force associated with the eddycurrent brake mechanism at the conductive containment [15]. This force can have more drastic effects than the aerodynamic drag if the conductive containment is not laminated. Parker et. al [16] introduced the infeasibility of employing conductive containments. They assert that loss of $\vec{F}_{n e t}$ due to eddy brake may be as large as $20 \%$ to $25 \%$. Even if infinitely thin laminations are utilized, the magnetic field suppression at the armature can not be reduced, which eventually reduces $\mathrm{L}_{\text {pr }}^{\prime}$ [17]. However, EMFY-3 has non-conductive containment; thus, electromagnetic drag can be neglected from (4). Mechanical state transformations are exhibited from (5) to (9), where $m_{l p}$ is the mass of the launch package. $\mathrm{T}_{\text {exit }}$ is the exit moment of the armature, $\mathrm{X}_{\text {pre }}$ is the pre-load position, and $\mathrm{x}_{\mathrm{rail}}$ is the rail length.

$$
\vec{F}_{n e t}=m_{l p} \vec{a}_{l p}
$$




$$
\begin{gathered}
\vec{a}_{l p}=\frac{L^{\prime} I_{\text {rail }}^{2}}{2 m_{l a}} \\
\vec{v}_{\text {arm }}=\int_{0}^{T_{\text {exit }}} \frac{L^{\prime} I_{\text {rail }}^{2}}{2 m_{l a}} d t \\
\vec{x}_{\text {arm }}=\int_{0}^{T_{\text {exit }}} \int_{0}^{T_{\text {exit }}} \frac{L^{\prime} I_{\text {rail }}^{2}}{2 m_{\text {la }}} d t d t \\
x(0)=X_{\text {pre }} \quad x\left(T_{\text {exit }}\right)=x_{\text {rail }}
\end{gathered}
$$

Considering (1-8), a kine-mechanical model is constructed. It should be noted that, the only design parameter is $L_{\mathrm{pr}}^{\prime}$ if $\mathrm{I}_{\text {rail }}$ measurements are used for 11 . $\mathrm{L}_{\mathrm{pr}}^{\prime}$ is calculated $0.515 \mu \mathrm{H} / \mathrm{m}$ from 3-D FE model. Three different launch test are used for analysis. Test parameters are given with their label in Table $\Pi$. Rail current measurements are illustrated in Fig. 4 .

TABLE II

TEST PARAMETERS

\begin{tabular}{ccc} 
& Peak Rail Current & PPS Energy \\
\hline Test A & $1,58 \mathrm{MA}$ & $8 \mathrm{MJ}$ \\
Test B & $1,90 \mathrm{MA}$ & $8 \mathrm{MJ}$ \\
Test C & $2,12 \mathrm{MA}$ & $8 \mathrm{MJ}$
\end{tabular}

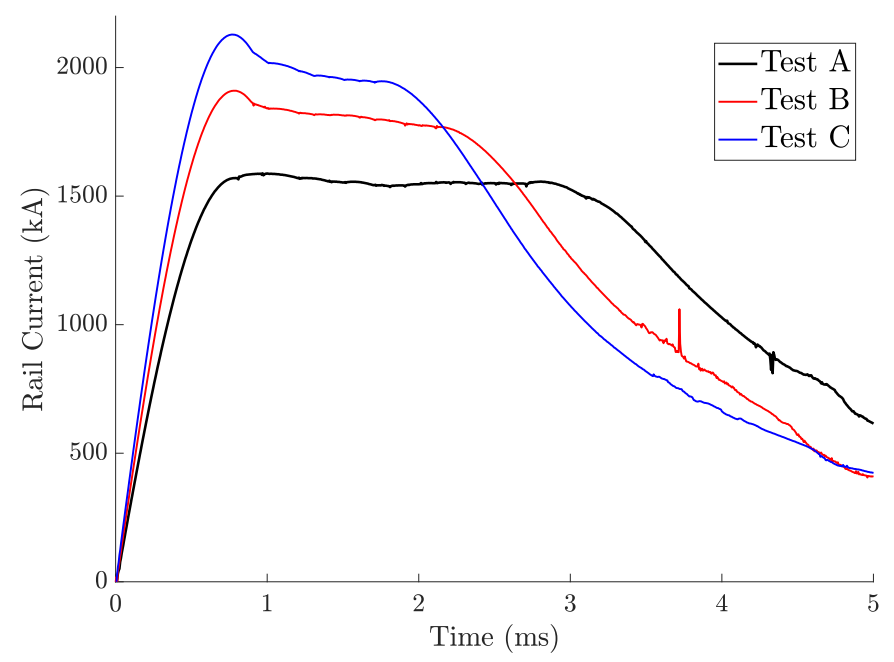

Fig. 4. Rail current measurements.

$\mathrm{C}_{\mathrm{d}}$ is dependent on the launch package geometry. It can be reduced with well-designed geometry, which improves efficiency. $\mathrm{C}_{\mathrm{d}}$ of an armature with a dummy weight can be approximated as 1. An example of armature with a dummy weight is illustrated in Fig. 5 .

Simulation results of the kine-mechanical model are illustrated with experimental velocity curves in Fig. 6. Red curves are used to demonstrate the simulation results where (2) is used. Blue curves, on the other hand, represent simulation results where $\vec{F}_{n e t}$ is equal to $\vec{F}_{p r}$, meaning that the friction and drag forces are neglected. Gray dashed vertical lines indicate the armature's exit moment, obtained from the muzzle and breech voltages. The effect of the $\vec{F}_{\text {fric }}$ can be understood from Test A-C, where the velocity measurement span is

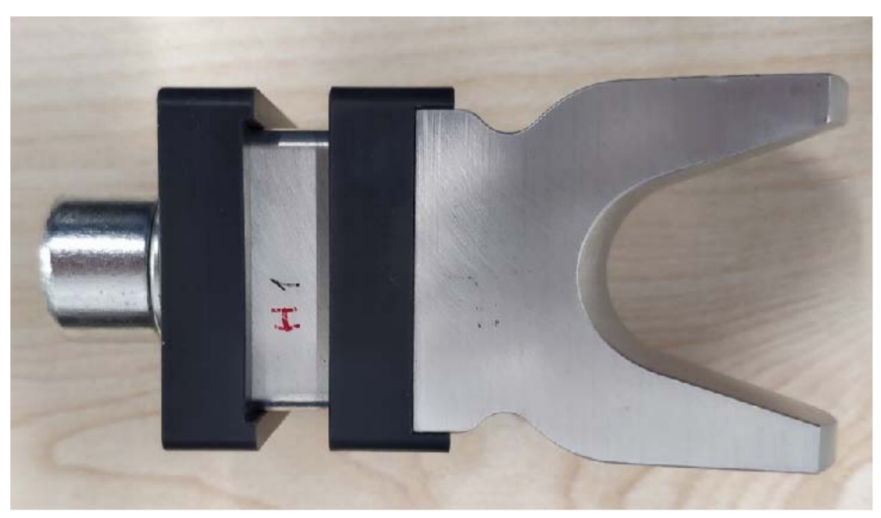

Fig. 5. An armature with dummy weight which is used for the EMFY-2 Launcher. [5].

TABLE III

THe Model Parameters

\begin{tabular}{llc} 
Parameter & Value & Description \\
\hline$C_{d}$ & 1 & Drag coefficient \\
$A_{l p}$ & $37.5 \mathrm{~cm}^{2}$ & Frontier area \\
$\rho_{\text {air }}$ & $1.225 \mathrm{~kg} /\left(\mathrm{m}^{3}\right)$ & Density of the air \\
$\mu_{d}$ & $0.3^{\dagger}$ & Dynamic friction coefficient \\
$\mu_{s}$ & $0.5^{\dagger}$ & Static friction coefficient \\
$\zeta$ & -0.01 & Damping coefficient \\
\hline
\end{tabular}

$\dagger \mu_{d}$, and $\mu_{s}$ are changing with contact state.

complete. Fig. 7 is used to better illustration of $\vec{F}_{\text {fric }}$ influence. There are negligible $\vec{F}_{d r a g}$ influence on the velocity curves; thus, blue curves show the effect of $\vec{F}_{\text {fric }}$ more dominantly. Exit velocities are overestimated Just a few dozens $\mathrm{m} / \mathrm{s}$ only, which has a slight influence. However, at the initial stage of the launch, the effect of $\vec{F}_{\text {fric }}$ is more dominant.

TABLE IV

SENSITIVITY RESULTS

\begin{tabular}{llll} 
& Test A & Test B & Test C \\
\hline Experiment $^{\dagger}$ & $2238 \mathrm{~m} / \mathrm{s}$ & $2312 \mathrm{~m} / \mathrm{s}$ & $2418 \mathrm{~m} / \mathrm{s}$ \\
Base Model $^{\ddagger}$ & $2225 \mathrm{~m} / \mathrm{s}$ & $2338 \mathrm{~m} / \mathrm{s}$ & $2470 \mathrm{~m} / \mathrm{s}$ \\
$\% 1$ & $2247 \mathrm{~m} / \mathrm{s}$ & $2361 \mathrm{~m} / \mathrm{s}$ & $2495 \mathrm{~m} / \mathrm{s}$ \\
$\%-1$ & $2202 \mathrm{~m} / \mathrm{s}$ & $2314 \mathrm{~m} / \mathrm{s}$ & $2445 \mathrm{~m} / \mathrm{s}$ \\
$\% 3$ & $2293 \mathrm{~m} / \mathrm{s}$ & $2409 \mathrm{~m} / \mathrm{s}$ & $2544 \mathrm{~m} / \mathrm{s}$ \\
$\%-3$ & $2157 \mathrm{~m} / \mathrm{s}$ & $2267 \mathrm{~m} / \mathrm{s}$ & $2395 \mathrm{~m} / \mathrm{s}$ \\
$\% 5$ & $2338 \mathrm{~m} / \mathrm{s}$ & $2456 \mathrm{~m} / \mathrm{s}$ & $2594 \mathrm{~m} / \mathrm{s}$ \\
$\%-5$ & $2112 \mathrm{~m} / \mathrm{s}$ & $2219 \mathrm{~m} / \mathrm{s}$ & $2345 \mathrm{~m} / \mathrm{s}$ \\
\hline
\end{tabular}

$\dagger$ These values are calculated with Doppler curves and muzzle voltages.

$\ddagger$ The base model uses $L_{p r}^{\prime}=0.515 / \mathrm{m}$.

Determination of $\mathrm{L}_{\mathrm{pr}}^{\prime}$ is critical for electromagnetic analysis. As the EML's inductance and resistance are increasing with armature motion. These variations are modelled as position gradients, i.e. $\mathrm{R}_{\text {rail }}^{\prime}$ represent rail resistance per meter, and $\mathrm{L}_{\mathrm{EML}}^{\prime}$ is used to model inductance change of the EML for $1-\mathrm{m}$ armature displacement. Armature movement is modeled with force equilibrium as in 22; thus, any variation from actual $L_{\mathrm{pr}}^{\prime}$ will introduce an error to the analysis. These errors influence simulated $\mathrm{I}_{\text {rail }}$ which affect (1) even more. To examine the sensitivity of $L_{p r}^{\prime}$ calculation on kine-mechanical calculation, 


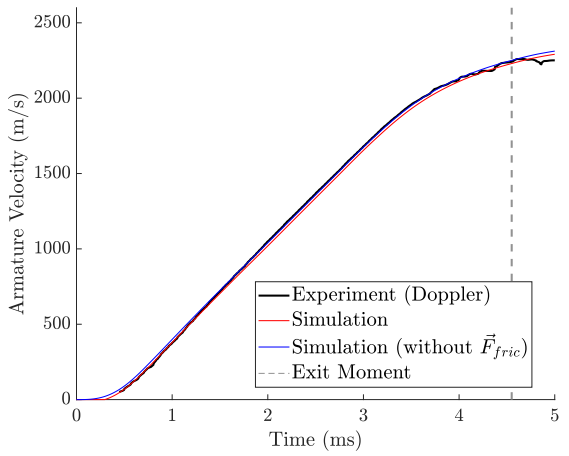

(a) Test A.

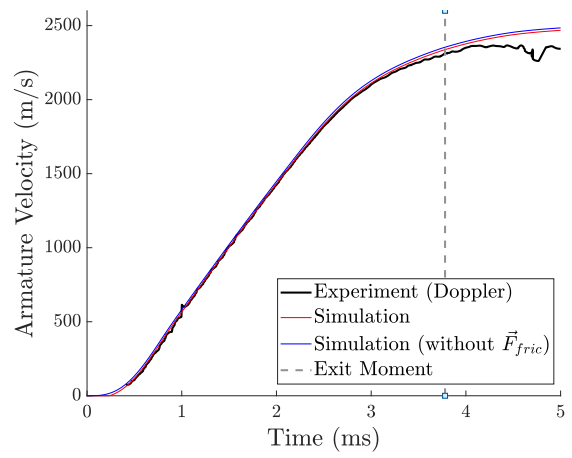

(b) Test B

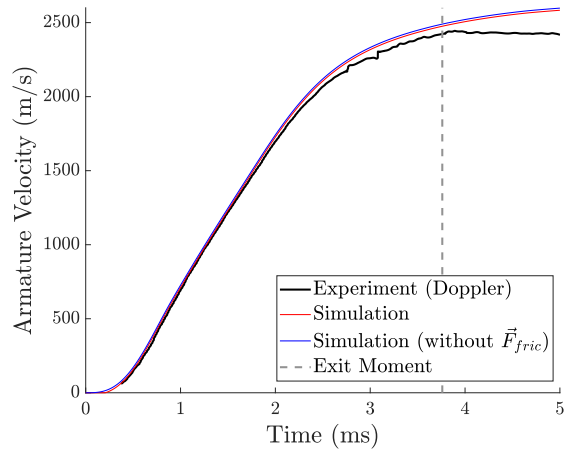

(c) Test C.

Fig. 6. Experimental and simulated velocity curves. Two different simulation model is used to demonstrate the effect of $\vec{F}_{f r i c}$. Exit moments are obtained experimental breech and muzzle voltages.

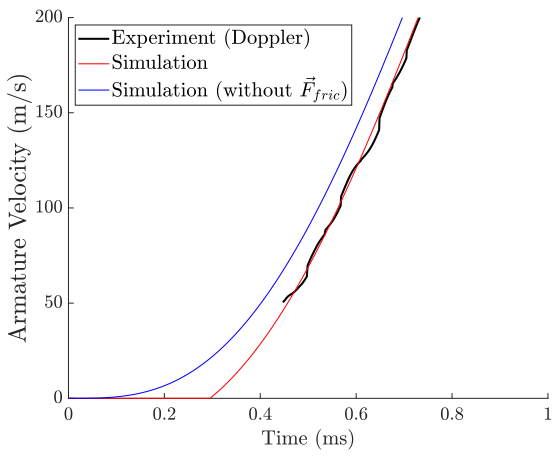

(a) Test A.

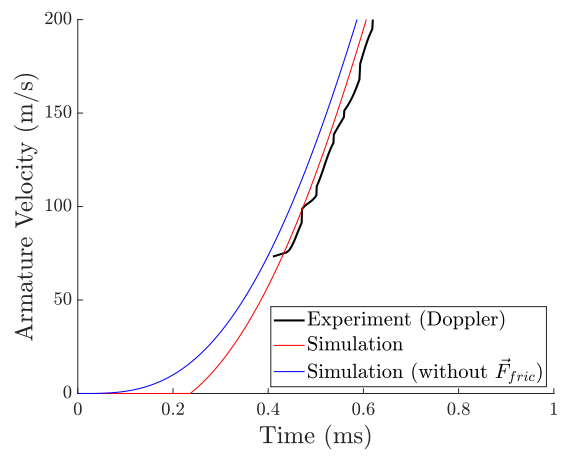

(b) Test B

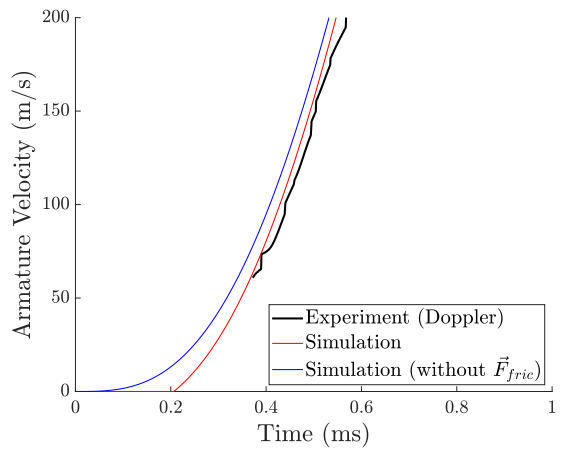

(c) Test C.

Fig. 7. Experimental and simulated velocity curves in the $0-1 \mathrm{~ms}$ interval.

seven different scenarios are used. The base model uses $\mathrm{L}_{\mathrm{pr}}^{\prime}$, which is calculated from the 3-D FE model. Moreover, $\pm 1 \%, \pm 3 \%$, and $\pm 5 \%$ calculation errors of $\mathrm{L}_{\mathrm{pr}}^{\prime}$ are examined individually. The results are demonstrated in Table IV in terms of muzzle velocities. In Fig. 8 velocity curves are illustrated with experimental measurements where each color represents a different test. Armature exit velocities with different $L_{\mathrm{pr}}^{\prime}$ deviations are illustrated with Box-Whisker plot in Fig. 9 Red lateral lines indicate Base Model, whereas blue lateral lines indicate $\pm 3 \%$ aberration from its base value. Black lines are used to show $\pm 5 \%$ deviation. Experimental values are indicated with points. It should be noted that tests are listed in ascending order in terms of rail current. It is clear that when $\mathrm{I}_{\text {rail }}$ is increased, the base model starts to overestimate $\mathrm{L}_{\mathrm{pr}}^{\prime}$. To investigate such effect, muzzle voltage measurements should be investigated as the primary suspect for such loss mechanism is considered transition.

\section{DISCUSSIONS}

The main focus of this paper is to investigate the importance of accurate calculation $\mathrm{L}_{\mathrm{pr}}^{\prime}$ for EML analysis. Moreover, any deviations in $\mathrm{L}_{\mathrm{pr}}^{\prime}$ are tried to understand from experimental measurements such as muzzle voltages. The compatibility of electromagnetic simulations with experimental findings is not the scope of this work, but it will be shared with a subsequent paper. In that paper, findings related with electromagnetic impacts of the bus geometry will be shared, as the effect has a significant influence on the simulation results.

$\vec{F}_{\text {fric }}$ calculation is simplified considering its net influence on the launch. $\mu_{d}$, and $\mu_{s}$ are not constant throughout the launch; they depend on the contact state. The contact state transition happened at $t=0.5 \mathrm{~ms}$, which is obtained from an analysis not covered here. Thus, $\mu_{d}$ and $\mu_{s}$ are diminished using a time-dependent step function.

\section{CONCLusions}

In this study, the importance of the correct $L_{p r}^{\prime}$ calculation is demonstrated by a sensitivity analysis. For this regard, a simplified kine-mechanical model is shared, which uses empirical data to examine $L_{p r}^{\prime}$ transients. Results show that $L_{p r}^{\prime}$ is constant launch to launch, whereas its value diminished slightly at the late stage of the launch. This $L_{p r}^{\prime}$ reduction is correlated with linear current density; higher the rail current corresponds with higher reduction. However, reductions are limited to $2 \%$, not as significant as eddy brakes due to the conductive environment. The transition phenomenon is the candidate for explaining the brake effect. The remarks which are obtained throughout the EMFY-3 experiments can be listed as:

1) Simulation models are susceptible to $L_{p r}^{\prime}$ accuracy. An $\% 5$ deviation from the actual value can cause muzzle velocity error up to $\% 6.23$. 


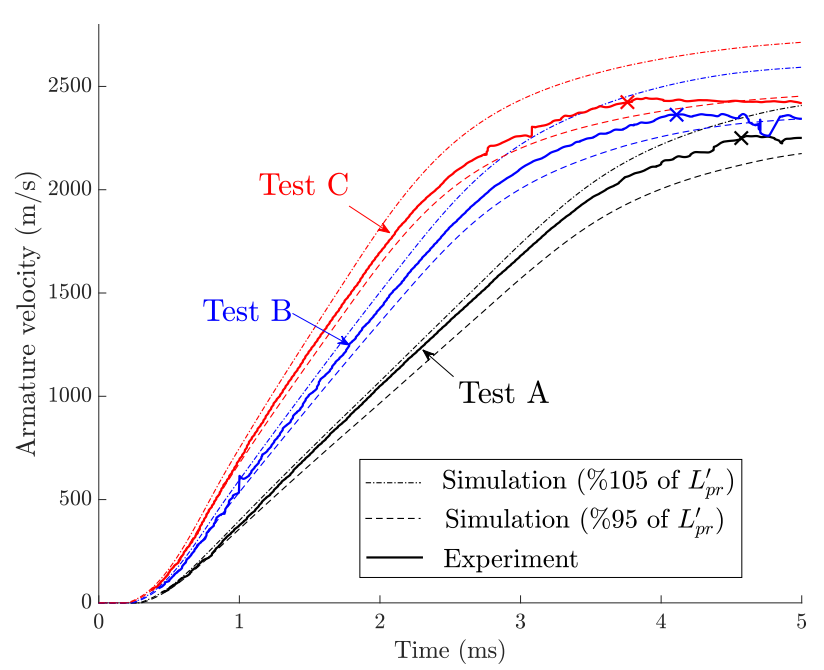

(a) $\% 5 \mathrm{~L}_{\mathrm{pr}}^{\prime}$ deviation.

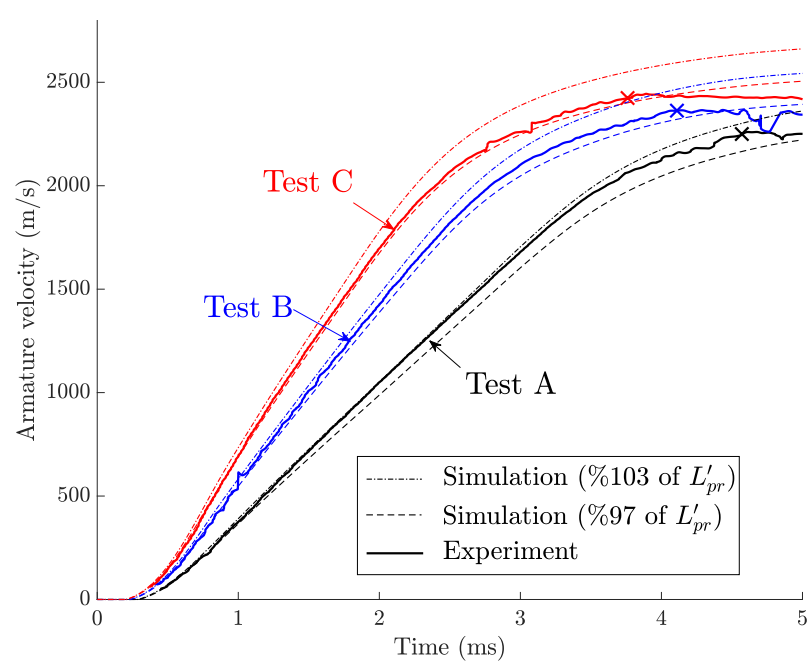

(b) $\% 3 \mathrm{~L}_{\mathrm{pr}}^{\prime}$ deviation.

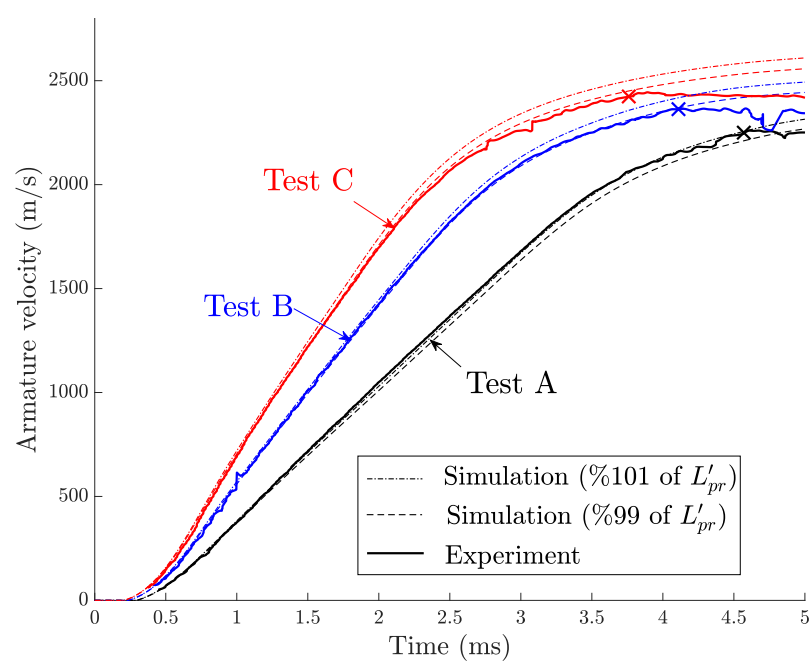

(c) $\% 1 \mathrm{~L}_{\mathrm{pr}}^{\prime}$ deviation.

Fig. 8. The effect of the $\mathrm{L}_{\mathrm{pr}}^{\prime}$ deviations on velocity curves. Exit moments are demonstrated with crosses with respecting colors.

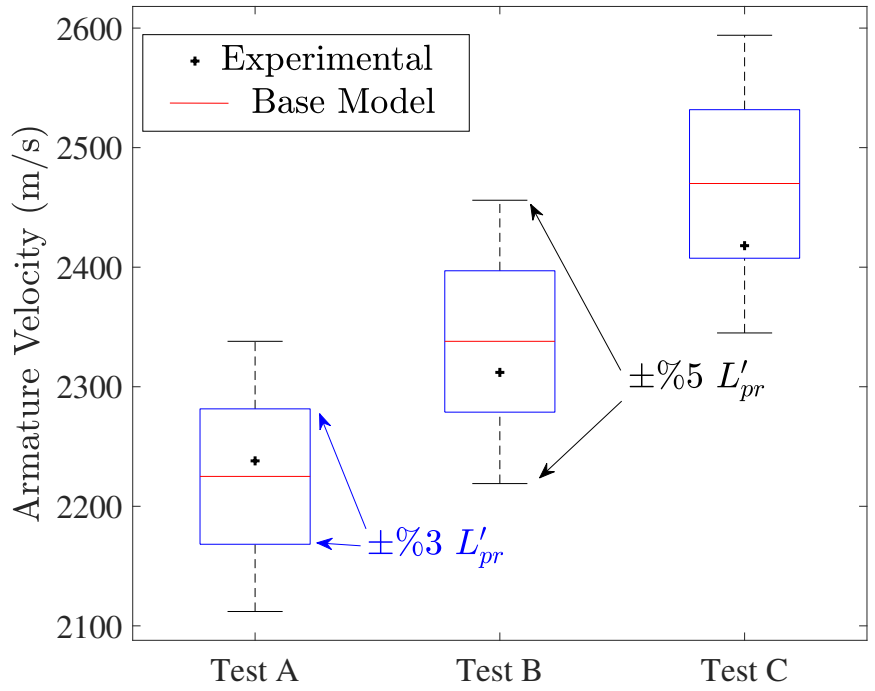

Fig. 9. The Box-Whisker plot. The effect of the $\mathrm{L}_{\mathrm{pr}}^{\prime}$ deviations on the armature exit velocities are shown.

2) Friction and aerodynamic forces are not dominant to determine muzzle velocities. Although friction forces influence the initial moments of the launch, aerodynamic forces do not affect kine-mechanical calculations.

3) $\mathrm{L}_{\mathrm{pr}}^{\prime}$ is constant throughout the launch as the containment is non-conductive. A slight decrease (up to \%2) is observed in Test $\mathrm{C}$, where $\mathrm{I}_{\text {rail }}$ exceeds 2.12 MA. A severe transition effect can explain such a decrease.

\section{ACKNOWLEDGMENT}

The authors would like to thank Umut Tureli, and the other ASELSAN Team members whose support made this article possible.

\section{REFERENCES}

[1] D. Ceylan, M. Karagöz, Y. Çevik, B. Yıldırım, H. Polat, and O. Keysan, "Simulations and experiments of emfy-1 electromagnetic launcher," IEEE Transactions on Plasma Science, vol. 47, no. 7, pp. 3336-3343, 2019.

[2] M. Karagoz, Y. Çevik, E. Tan, A. Civil, O. Cavbozar, U. Gocmen, B. Yildirim, E. Durna, and M. Sahin, "Aselsan emfy-1 electromagnetic launcher: First experiments," in 2017 IEEE 21st International Conference on Pulsed Power (PPC), 2017, pp. 1-3.

[3] A. Civil, Cavbozar, M. Karagöz, E. Tan, and Y. Çevik, "Design and improvement of a pulse shaping inductor for a pulsed power system," in 2017 IEEE 21st International Conference on Pulsed Power (PPC), 2017, pp. 1-3.

[4] E. Durna, Y. Çevik, M. Karagöz, and A. Civil, "Design and implementation of a hierarchical control system architecture for a modular pulsed power supply system," in 2016 IEEE International Power Modulator and High Voltage Conference (IPMHVC), 2016, pp. 594-597.

[5] M. Karagoz, A. Civil, B. Yildirim, E. B. Yurdakul, E. Durna, E. Tan, O. Cavbozar, U. Gocmen, and Y. Cevik, "Aselsan electromagnetic launch laboratory: First shot," IEEE Transactions on Plasma Science, vol. 48, no. 4, pp. 802-807, 2020.

[6] N. Tosun, H. Polat, D. Ceylan, M. Karagoz, B. Yıldırım, Güngen, and O. Keysan, "A hybrid simulation model for electromagnetic launchers including the transient inductance and electromotive force," IEEE Transactions on Plasma Science, vol. 48, no. 9, pp. 3220-3228, 2020.

[7] N. Tosun, D. Ceylan, H. Polat, and O. Keysan, "A comparison of velocity skin effect modeling with 2-d transient and 3-d quasi-transient finite element methods," IEEE Transactions on Plasma Science, vol. 49, no. 4 pp. 1500-1507, 2021. 
[8] S. An, B. Lee, Y. Bae, Y. Lee, and S. Kim, "Numerical analysis of the transient inductance gradient of electromagnetic launcher using 2-d and 3-d finite-element methods," IEEE Transactions on Plasma Science, vol. 45, no. 7, pp. 1635-1638, 2017.

[9] J. Barber, D. Bauer, K. Jamison, J. Parker, F. Stefani, and A. Zielinski, "A survey of armature transition mechanisms," IEEE Transactions on Magnetics, vol. 39, no. 1, pp. 47-51, 2003.

[10] J. Ruan, L. Chen, Z. Wang, C. Li, P. Wu, and S. Xia, "Transition mechanism based on load imbalance of liquid metal film," IEEE Transactions on Plasma Science, vol. 48, no. 10, pp. 3720-3726, 2020.

[11] C. Li, L. Chen, J. Xu, J. Ruan, P. Wu, Z. Wang, and S. Xia, "Influence of caliber height on armature current melt erosion in rail gun," IEEE Transactions on Plasma Science, vol. 48, no. 8, pp. 2932-2938, 2020.

[12] Z. Wang, L. Chen, S. Xia, and C. Li, "Experiments and analysis of downslope low-voltage transition in c-type solid armature rail gun," IEEE Transactions on Plasma Science, vol. 48, no. 7, pp. 2601-2607, 2020 .
[13] S. Xia, Y. Hu, L. Chen, J. He, Z. Yuan, H. He, P. Yan, and J. Li, "Experimental studies on melt erosion at rail-armature contact of rail launcher in current range of 10-20 ka/mm," IEEE Transactions on Plasma Science, vol. 45, no. 7, pp. 1667-1672, 2017.

[14] J. Wu, G. Wan, N. Cheng, L. Li, and B. Li, "Research on armature's wearing and dynamic interior ballistic of a railgun," IEEE Transactions on Plasma Science, vol. 45, no. 7, pp. 1202-1207, 2017.

[15] D. Landen and S. Satapathy, "Eddy current effects in the laminated containment structure of railguns," IEEE Transactions on Magnetics, vol. 43, no. 1, pp. 150-156, 2007.

[16] J. V. Parker and S. Levinson, "Loss of propulsive force in railguns with laminated containment," IEEE Transactions on Magnetics, vol. 35, no. 1, pp. 442-446, 1999.

[17] J. Mallick, "Phenomenological electromagnetic modeling of laminatedcontainment launchers," IEEE Transactions on Magnetics, vol. 43, no. 1, pp. 359-363, 2007. 